\title{
Proposta conceitual de colhedoras autopropelidas de açaí (Euterpe oleracea Mart.) para a Região Amazônica ${ }^{1}$
}

\author{
A conceptual proposal for self-propelled açai (Euterpe oleracea Mart.) harvesters for \\ the Amazon Region
}

\author{
Daniel Albiero $^{2 *}$, Antonio José da Silva Maciel $^{3}$, Renildo Luiz Mion², Carlos Alberto Viliotti² e Carlos Antonio \\ Gamero $^{4}$
}

\begin{abstract}
Resumo - A produção de frutos de açaí é proveniente, em sua maioria, do extrativismo, mas existe uma forte tendência de implementação de cultivos comerciais. A colheita dos frutos é realizada exclusivamente por escaladores, que se arriscam a sofrer acidentes, além de não terem grande eficiência na colheita. O objetivo deste trabalho foi realizar os desenhos conceituais de colhedoras autopropelidas de açaís em ambientes de matas de terra firme, matas de várzea e cultivos comerciais. Para tal foi utilizada a metodologia de projeto de matriz morfológica. Como resultados foram obtidos os desenhos conceituais destas novas colhedoras: Colhedora de açaí para matas de várzea nativas em estação de cheia; Colhedora de açaí para matas de terra firme nativas e matas de várzea em estação de seca; Colhedora de açaí para cultivos comerciais.
\end{abstract}

Palavras-chave - Açaí. Máquinas Agrícolas. Amazônia.

\begin{abstract}
Production of the açai fruit is mainly accomplished through manual collection; but there is a strong trend towards the implementation of commercial crops. Fruit harvesting is carried out exclusively by climbers who risk injury to themselves, besides not being very efficient at harvesting. The aim of this study was to produce design concepts for self-propelled açai harvesters for dry-land forest environments, floodplain forest environments and commercial crops. To this end we used the design methodology of a morphological matrix. The results obtained were the design concepts for the following new harvesters: an açai harvester for native floodplain forests in the wet season; a harvester for both dry-land and native floodplain forests in the dry season; a harvester for commercial crops.
\end{abstract}

Key words - Açaí. Agricultural Machines. Amazon.

\footnotetext{
* Autor para correspondência

Recebido para publicação em 15/09/2010; aprovado em 31/08/2011

Pesquisa financiada pela Faculdade de Engenharia Agrícola da Universidade Estadual de Campinas

2Departamento de Engenharia Agrícola/DENA-UFC, Bloco 804, Campus do Pici, Fortaleza-CE, Brasil, 60.455-760, dalbiero@ufc.br, rmion@ufc.br, viliotti@ufc.br

${ }^{3}$ Faculdade de Engenharia Agrícola/FEAGRI-UNICAMP, Cidade Universitária Zeferino Vaz, Campinas-SP, Brasil, 13.083-875, amaciel@ feagri. unicamp.br

${ }^{4}$ Departamento de Engenharia Rural/FCA-UNESP, Campus de Botucatu, Botucatu-SP, Brasil, 18.610-310, gamero@ reitoria.unesp.br
} 


\section{Introdução}

O açaizeiro (Euterpe oleracea Mart.) é uma Arecaceae típica do Norte do Brasil, cujos frutos são pequenos, arredondados e de coloração roxo-escuro em função da presença de pigmentos naturais (SOUZA et al., 2006). Segundo Nogueira (2009) o açaizeiro é nativo da Amazônia brasileira e necessita de umidade satisfatória no solo, como nas várzeas onde é nativo (MULLER, 2009). O Estado do Pará é o principal centro de dispersão natural dessa palmácea (MIRANDA; RABELO, 2008) e segundo Queiroz e Melém Jr. (2001) o açaizeiro pode ser apontado como a palmeira de maior importância cultural, econômica e social na Região Norte. Ribeiro et al. (2007) afirma que a conservação das florestas tropicais é um dos maiores desafios da humanidade, devido ao delicado equilíbrio que precisa ser estabelecido entre um ecossistema complexo e frágil e uma população rural pobre.

Segundo Nogueira (2009) cerca de $80 \%$ da produção de frutos têm origem no extrativismo, enquanto os $20 \%$ restantes são provenientes de açaizais manejados e cultivados em várzea e terra firme e Vasconcelos e Alves (2009) afirmam que a colheita de açaí é uma operação onerosa e difícil, pois os estipes atingem facilmente de 10 a 15 metros de altura.

A colheita mecanizada de frutos é um complexo desafio de engenharia, principalmente pelas peculariedades dos diversos tipos de frutos, assim como pela fragilidade dos mesmos (SRIVASTAVAS et al., 2006). Peloia et al. (2010) afirmam que as perdas na colheita estão intimamente ligadas à adequação ou não da máquina aos frutos. Neste contexto Neves (2004) classifica as perdas em duas categorias, as perdas visíveis e invisíveis. Na colheita de frutos, ambos tipos de perdas podem ocorrer, tanto para os frutos que foram destruídos ou ficaram no solo (visíveis), como aqueles que sofreram alguma solicitação exagerada que ocasionará sua deterioração prematuramente (invisíveis).

Durante o processo de pesquisa a fase essencial é a modelagem da máquina que subentende a determinação das relações funcionais fundamentais (VOLPATO et al., 2005). Srivastava et al. (2006) descrevem que os principais processos funcionais de uma colhedora de frutos são: processos de remoção; processos de controle; processos de seleção; e processos de transporte. $\mathrm{O}$ desenvolvimento de uma colhedora de açaí, necessariamente tem que ser imaginada em relação às colhedoras de frutos arbóreos.

Uma das metodologias mais utilizadas para organização e seleção de hipóteses de projeto é a matriz morfológica (PAHL et al., 2005) que é uma matriz onde as linhas são associadas às funções respectivas de uma máquina e as colunas hipóteses de variação dos parâmetros de funcionamento. Estas matrizes são classificadoras e ordenadoras e o desdobramento destes parâmetros possibilitam a conceituação de diversas soluções de engenharia (BACK, 1983). Segundo Pahl et al. (2005) o procedimento para a implementação de uma matriz morfológica é: 1- Idéias de soluções para as funções da máquina são lançadas nas linhas da coluna; 2- Possibilidades de mecanismos ou processos são lançados nas colunas; 3- Ordenação das diversas possibilidades de mecanismos ou processos em função das soluções das funções, o que determina diversos caminhos de projeto, estes caminhos de projeto são analisados e o melhor para os requisitos de projeto é selecionado.

O objetivo deste trabalho foi propor conceitos de colhedoras autopropelidas de açaís em ambientes de matas de terra firme, matas de várzea e cultivos comerciais.

\section{Material e métodos}

O fluxograma do estudo conceitual das colhedoras de açai é apresentado na Figura 1.

Considerou-se os seguintes parâmetros de projeto: 1-Altura dos cachos: $20 \mathrm{~m}$; 2- Densidade de plantas: $60 \pm 19$ indivíduos ha-1 e na floresta de Terra firme igual a $28 \pm 9$ ha $^{-1}$ (ROCHA, 2004); 3-Produção: Rocha (2004) obteve a média de produção de cachos de 1,8 na floresta de terra firme e 2,4 cachos no baixio (CASTRO, 2000) e o peso médio total dos cachos por palmeira na floresta de baixio foi de 7,5 $\pm 4,2 \mathrm{~kg}$ e na floresta de terra firme foi de $6,2 \pm 2,4 \mathrm{~kg}$.

Considerando os ambientes de produção definidos por Silva et al. (2007) e Viegas et al. (2004), foram definidas 3 linhas de projeto distintas, relativas aos 4 principais ambientes onde o açaí pode ser encontrado: 1- Matas de terra firme nativas manejadas; 2- Matas de várzea nativas manejadas em estação seca; 3- Matas de várzea nativas manejadas em estação de cheia; 4- Cultivos comerciais. Pretende-se que a colhedora de matas de terra firme seja capaz de colher em matas de várzea em estação seca. Assim, foram construídas 3 matrizes morfológicas preliminares.

Neste trabalho foi seguida a metodologia de projeto da matriz morfológica descrita por Albiero et al. (2007), que permitiu serem feitos os desenhos conceituais das colhedoras.

As matrizes morfológicas possibilitaram descrever a conceituação preliminar das colhedoras de açaí para cada ambiente nas seguintes proposições:

1- Colhedora de açaí para matas de várzea nativas em estação de cheia: $\mathrm{O}$ sistema de corte dos cachos de açaí será constituído por correntes denteadas devido a facilidade de operação e dimensionamento da fonte de 
Figura 1 - Fluxograma das fases do estudo de viabilidade técnica para as colhedoras de açaí

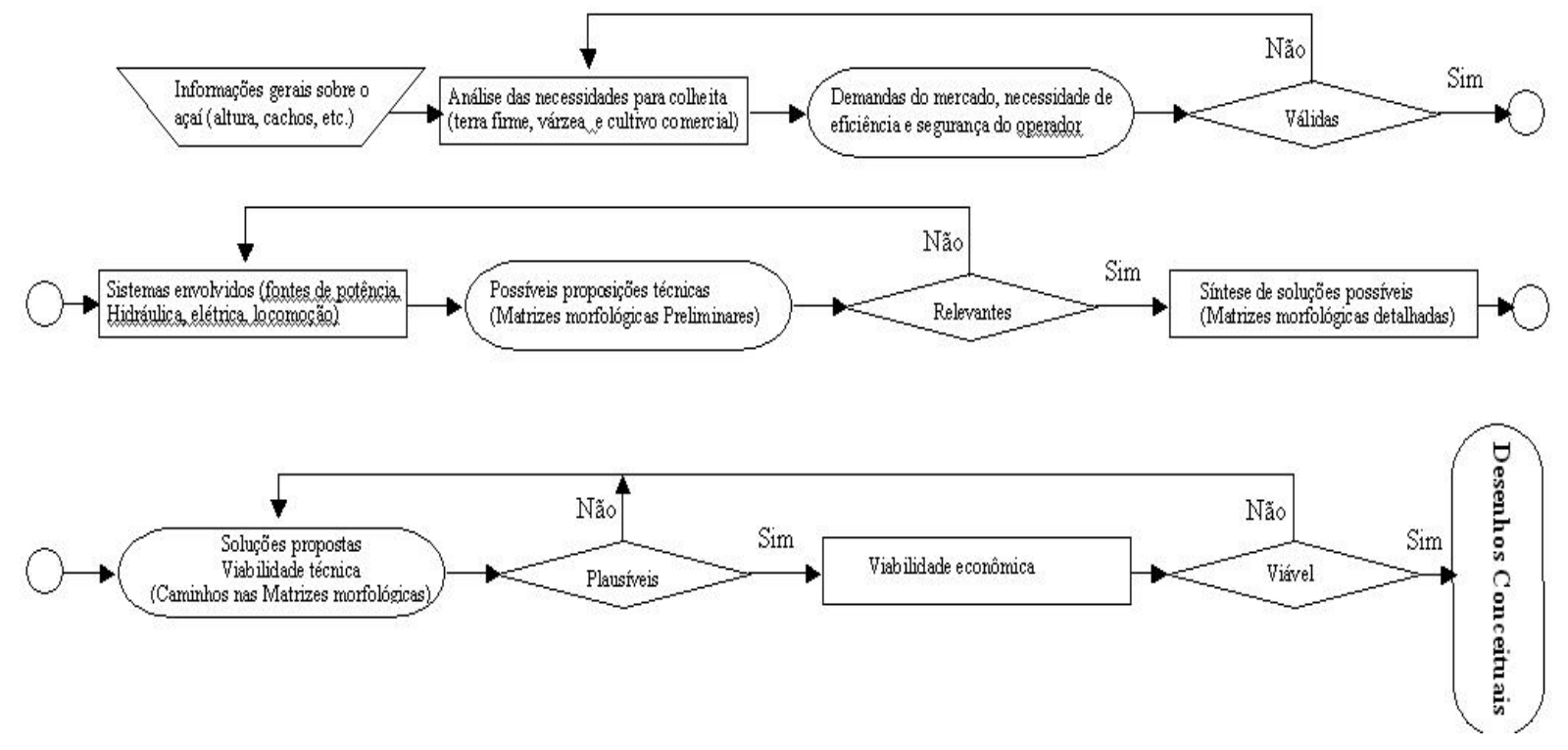

potência. O sistema de corte será elevado à altura de corte de $20 \mathrm{~m}$, através de um sistema cilindros hidráulicos. A energia para acionar a máquina será de combustão interna de combustíveis líquidos, devido a disponibilidade e custo dos motores de combustão interna atuais, além da possibilidade da utilização de biocombustíveis líquidos tais como o biodiesel e álcool.

O sistema de locomoção será por intermédio de um de barco devido à possibilidade de colheita no período de cheia, apenas um operador tem capacidade de operar a máquina por comandos mecânicos e eletro-hidráulicos; a fonte de energia para a máquina é um conjunto motor formado por motor de combustão interna ligado a um gerador de energia elétrica e a uma bomba hidráulica de deslocamento positivo; o sistema motriz da embarcação será por um conjunto motor CI e gerador elétrico.

Os mecanismos de colheita terão 3 graus de liberdade (XYZ) para possibilitarem uma maior precisão no alinhamento dos sistemas de elevação e de corte, assim facilitando o posicionamento do sabre de moto-serra sobre o pendúculo do cacho, estes mecanismos serão suportados por uma base acoplada ao barco. O recolhimento dos cachos de açaís será realizado por outro barco.

2-Colhedora de açaí para matas de terra firme nativas e matas de várzea em estação de seca: $\mathrm{O}$ sistema de corte dos cachos de açaí será constituído por correntes denteadas devido a facilidade de operação e dimensionamento da fonte de potência e será elevado à altura de corte de $20 \mathrm{~m}$, através de um sistema de cilindros hidráulicos. A energia para acionar a máquina será de combustão interna de combustíveis líquidos.
O sistema de locomoção será automotor, apenas um operador tem capacidade de operar a máquina por comandos eletro-hidráulicos; a fonte de energia para a máquina é um conjunto motor formado por motor de combustão interna ligado a uma bomba hidráulica de deslocamento positivo, o sistema motriz será um motocultor de pequeno porte com menos de $30 \mathrm{cv}$, que possibilitará o adequado fornecimento de energia para os sistemas atrelados além de constituir um equipamento de pequenas dimensões possibilitando a movimentação por entre as árvores intrincadas da selva. Os mecanismos de colheita terão 3 graus de liberdade (XYZ) e serão suportados por um chassi acoplado ao motocultor. O recolhimento dos cachos de açaís será realizado manualmente no chão.

3-Colhedora de açaí para cultivos comerciais: O sistema de corte dos cachos de açaí será constituído por correntes denteadas que será elevada a altura de corte de $20 \mathrm{~m}$, através de um sistema de cilindros hidráulicos. A energia para acionar a máquina será de combustão interna de combustíveis líquidos. O sistema de locomoção será automotor, apenas um operador tem capacidade de operar a máquina através de comandos eletro-hidráulicos, a fonte de energia para a máquina é um conjunto motor formado por motor de combustão interna ligado a uma bomba hidráulica de deslocamento positivo; o sistema motriz será por um trator com potência entre 50 e $100 \mathrm{cv}$, que possibilitará energia suficiente para as tarefas demandadas em função da estimativa de solicitações a que a colhedora poderá vir a sofrer. Os mecanismos de colheita terão 3 graus de liberdade (XYZ) e serão suportados pelo trator. O recolhimento dos cachos de açaís será realizado por um sistema mecânico acoplado ao próprio trator. 
As proposições 1; 2 e 3 foram consideradas relevantes, por conseguinte foram construídas as matrizes morfológicas detalhadas para cada proposição que possibilitaram descrever a conceituação detalhada das colhedoras de açaí para cada ambiente, nas seguintes proposições:

1.1-Colhedora de açaí para matas de várzea nativas em estação de cheia: O sistema de corte dos cachos de açaí será constituído por correntes denteadas de elo duplo cortante (tipo motosserra) que será elevada à altura de corte através de um sistema cilindro hidráulico composto com três graus de liberdade de movimento (XYZ), o acionamento do sistema de corte será por mecanismos eletro-hidráulicos, sendo a corrente suportada por um sabre (tipo motosserra). A energia para acionar a máquina será de combustão interna de um motor à gasolina de $20 \mathrm{cv}$.

O sistema de locomoção será através de barco tipo aerobarco com casco de baixo calado devido à possibilidade de colheita no período de cheia em florestas alagadas (com tocos submersos), apenas um operador tem capacidade de operar o aerobarco/colhedora através de comandos mecânicos para a embarcação, elétricos para o sistema de corte e hidráulicos para o cilindro composto, este operador se posicionará sentado na popa da embarcação, a fonte de energia para a máquina é um conjunto motor formado por motor de combustão interna ligado a um gerador de energia elétrica e a uma bomba hidráulica de deslocamento positivo.

O reservatório de óleo hidráulico ficará embutido no casco do aerobarco, o sistema motriz da embarcação será através do conjunto motor CI e gerador elétrico. Os mecanismos de colheita terão 3 graus de liberdade (XYZ) e serão suportados por uma base acoplada ao barco. O recolhimento dos cachos de açaís será realizado por outro barco.

2.2-Colhedora de açaí para matas de terra firme nativas e matas de várzea em estação de seca: $\mathrm{O}$ sistema de corte dos cachos de açaí será constituído por correntes denteadas de elo duplo cortante (tipo motosserra) que será elevada à altura de corte através de um sistema cilindro hidráulico composto com três graus de liberdade de movimento (XYZ), o acionamento do sistema de corte será por mecanismos eletro-hidráulicos, sendo a corrente suportada por um sabre (tipo motosserra). A energia para acionar a máquina será de um motor à combustão interna de diesel de $20 \mathrm{cv}$.

O sistema de locomoção será automotor através de um motocultor da marca Yanmar. Apenas um operador tem capacidade de operar a máquina através de comandos mecânicos para o motocultor, elétricos para o sistema de corte e hidráulicos para o cilindro composto. Este operador se posicionará sentado no chassi acoplado ao motocultor; a fonte de energia para a máquina é um conjunto motor formado por motor de combustão interna ligado a uma bomba hidráulica de deslocamento positivo, o sistema motriz será de pequeno porte devido à necessidade da máquina se mover por entre as árvores intrincadas da selva.

Os mecanismos de colheita terão 3 graus de liberdade (XYZ) e serão suportados por um chassi acoplado ao motocultor. O recolhimento dos cachos de açaís será realizado manualmente no chão. A conceituação e detalhamento desta proposta foi objeto do desenvolvimento de uma colhedora de babaçu, apresentada por Albiero et al. (2011).

3.3-Colhedora de açaí para cultivos comerciais: O sistema de corte dos cachos de açaí será constituído por correntes denteadas de elo duplo cortante (tipo motosserra) que será elevada à altura de corte através de um sistema cilindro hidráulico composto com três graus de liberdade de movimento (XYZ), o acionamento do sistema de corte será por mecanismos eletro-hidráulicos, sendo a corrente suportada por um sabre (tipo motosserra). A energia para acionar a máquina será de um motor à combustão interna de diesel de $75 \mathrm{cv}$.

O sistema de locomoção será automotor através de um trator da marca Green Horse, apenas um operador tem capacidade de operar a máquina através de comandos mecânicos para o trator, elétricos para o sistema de corte e hidráulicos para o cilindro composto, este operador se posicionará sentado em uma plataforma acoplada ao chassi da máquina, a fonte de energia para a máquina é um conjunto motor formado por motor de combustão interna ligado a uma bomba hidráulica de deslocamento positivo.

Os mecanismos de colheita terão 3 graus de liberdade (XYZ) e serão suportados pelo trator. O recolhimento dos cachos de açaís será realizado por um sistema mecânico acoplado ao próprio trator.

Todos os componentes escolhidos para definição do caminho de projeto de cada umas das proposições 1.1; 2.2 e 3.3 foram definidas em função de considerações técnicas-econômicas e ambientais, já que todas as soluções apresentadas têm suporte no estado da técnica da engenharia, são proposições conceituais factíveis de serem construídas. Assim foram feitos os desenhos conceituais das colhedoras propostas.

\section{Resultados e discussão}

As colhedoras de açaí são apresentadas nas Figuras 2; 3 e 4. São apresentados também projeções ortogonais de cada máquina, assim como simulações de operação (FIG. 5; 6 e 7). 
Figura 2 - Colhedora de açaí para ambientes de matas de terra firme e matas de várzea em estação seca: sabre de moto-serra (1), base elétrica do cabeçote de corte (2), caixa do comando elétrico (3), comando hidráulico de 9 elementos (4), motocultor (5), pistão composto telescópico (6), base hidráulica rotativa (7), roda suporte (8), chassi traseiro e esteira de borracha (9), reservatórios de óleo hidráulico (10), discos de direção para terreno alagado (11), roda de direção para terreno firmo (12), chassi frontal (13)

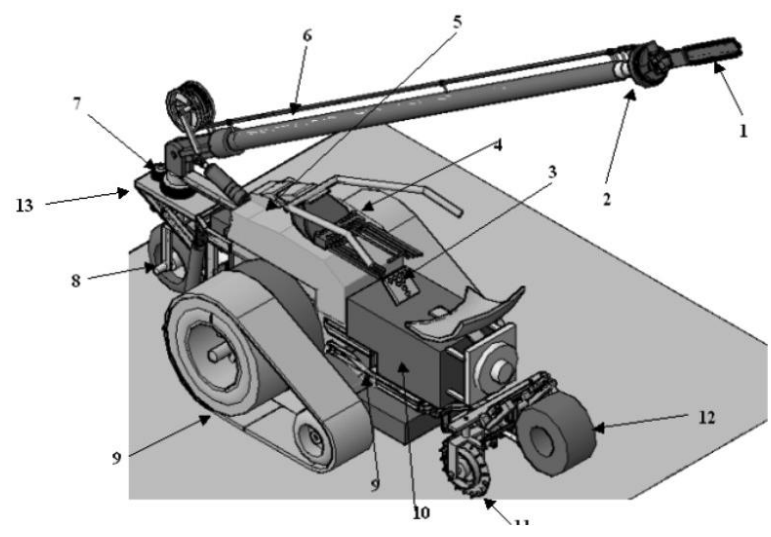

Figura 3 - Colhedora de açaí para ambientes de matas de várzea em estação de cheia: pistão telescópico do flutuador (1), casco do aerobarco (2), comando hidráulico de 9 elementos (3), comando mecânico do leme (4), pistão composto telescópico do corte (5), base elétrica do cabeçote de corte e sabre de moto-serra (6), leme (7), proteção da hélice (8), hélice aeronáutica (9), flutuador de equilíbrio (10), assento do piloto (11), comando elétrico do corte (12), base hidráulica rotativa (13), escudo de proteção frontal (14)

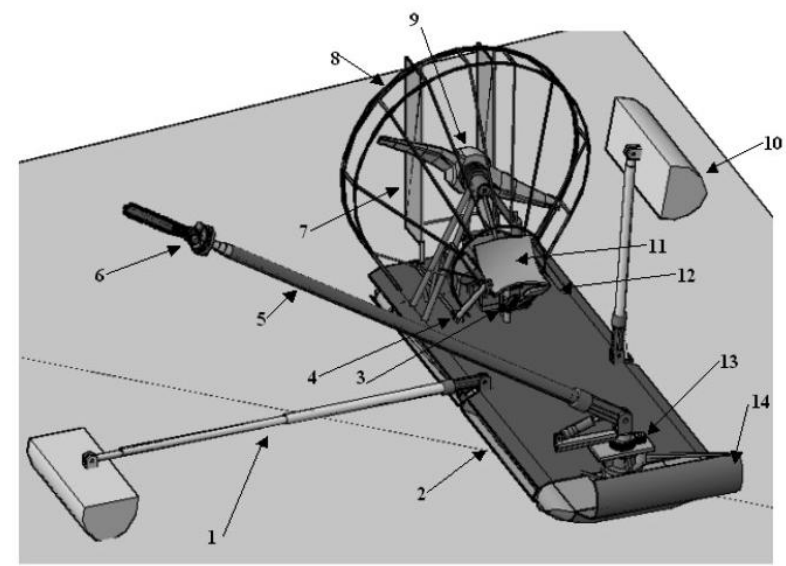

Figura 4 - Colhedora de açaí para ambientes de cultivo comercial: lona para coleta dos cachos de açaí (1), pistão telescópico para recolher e estender a lona (2), base de elétrica de corte e sabre de moto-serra (3), chassi da colhedora (4), plataforma de comando (5), comando elétrico do corte (6), comando mecânico do trator (7), comando hidráulico de 9 elementos (8), base hidráulica rotativa (9), trator (10), tanque de óleo hidráulico (11), reservatório de açaís (12), esteira de transporte de açaís (13), roda suporte do chassi (14), pistão composto telescópico do corte (15)

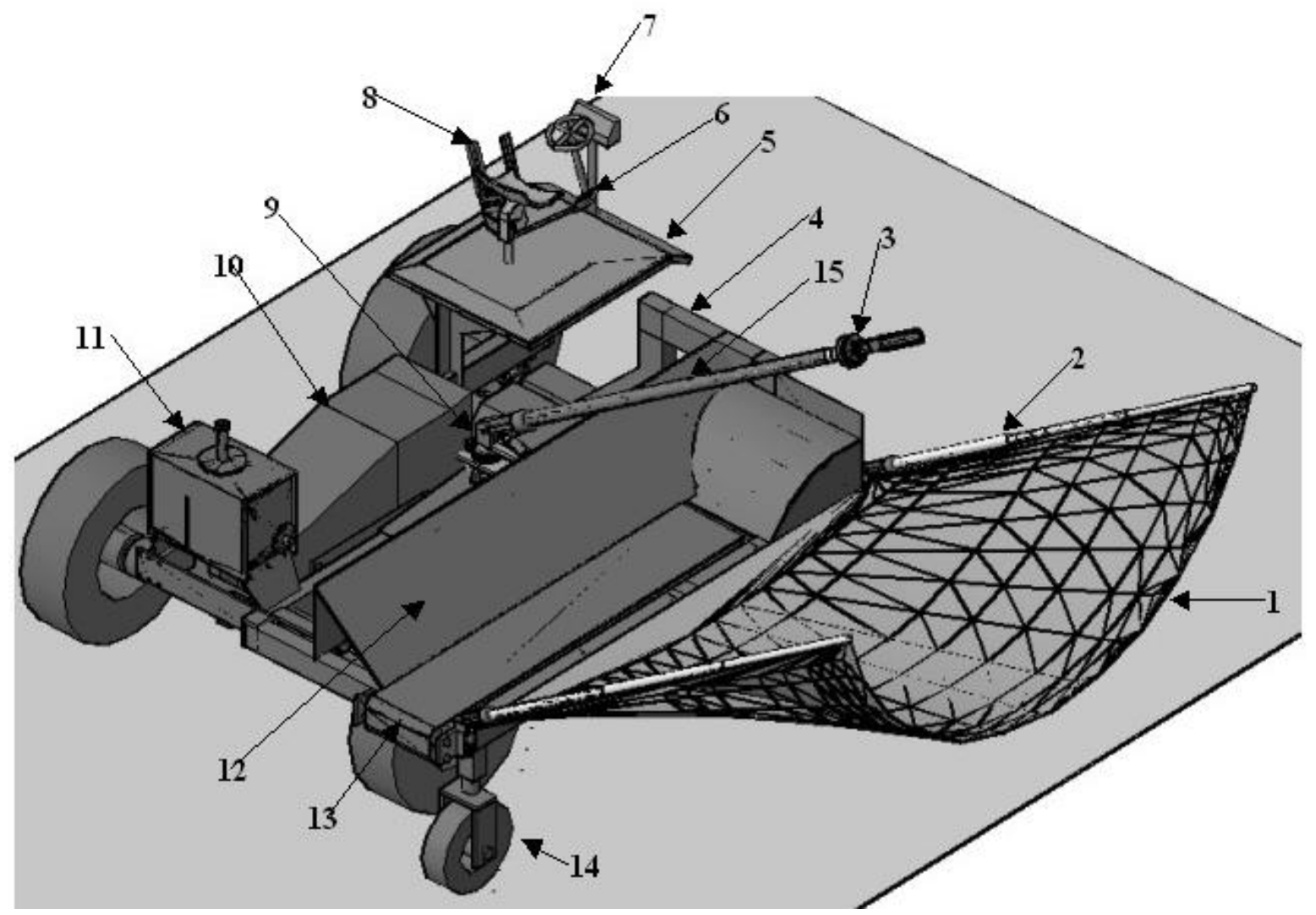


Figura 5 - (a) Projeções ortogonais da colhedora de açaí para ambientes de matas de terra firme e matas de várzea em estação seca, (b) Simulação da colhedora de açaí para matas de terra firme em ação

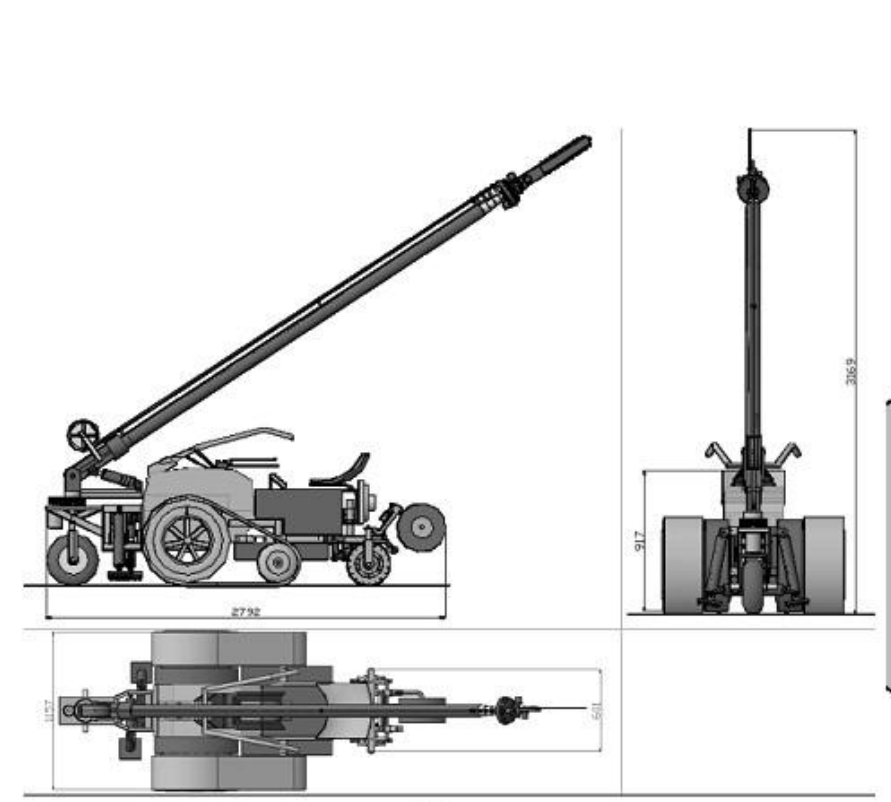

(a)

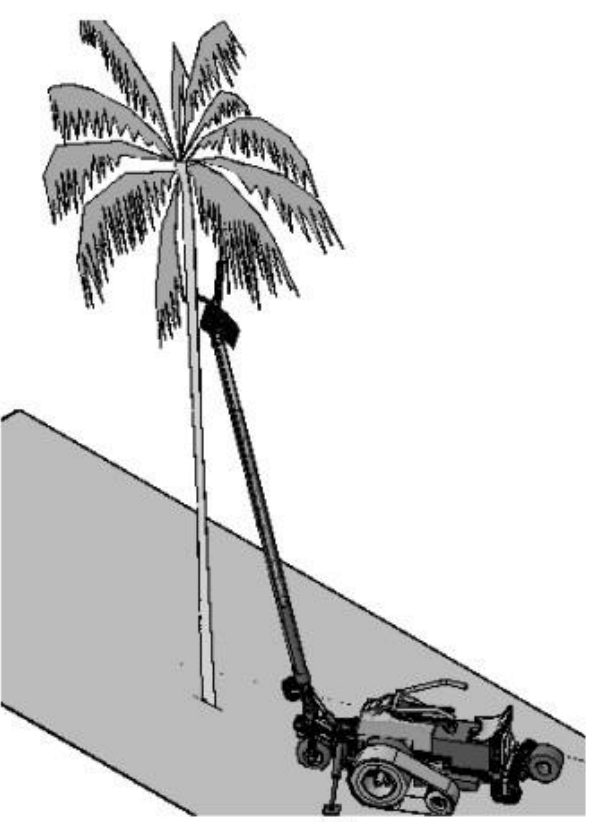

(b)

Figura 6 - (a) Projeções ortogonais da colhedora de açaí para ambientes de matas de várzea em estação de cheia, (b) Simulação da colhedora de açaí para várzeas alagadas em ação, notar o aerobarco com reservatório para cachos de açaí em apoio à colhedora

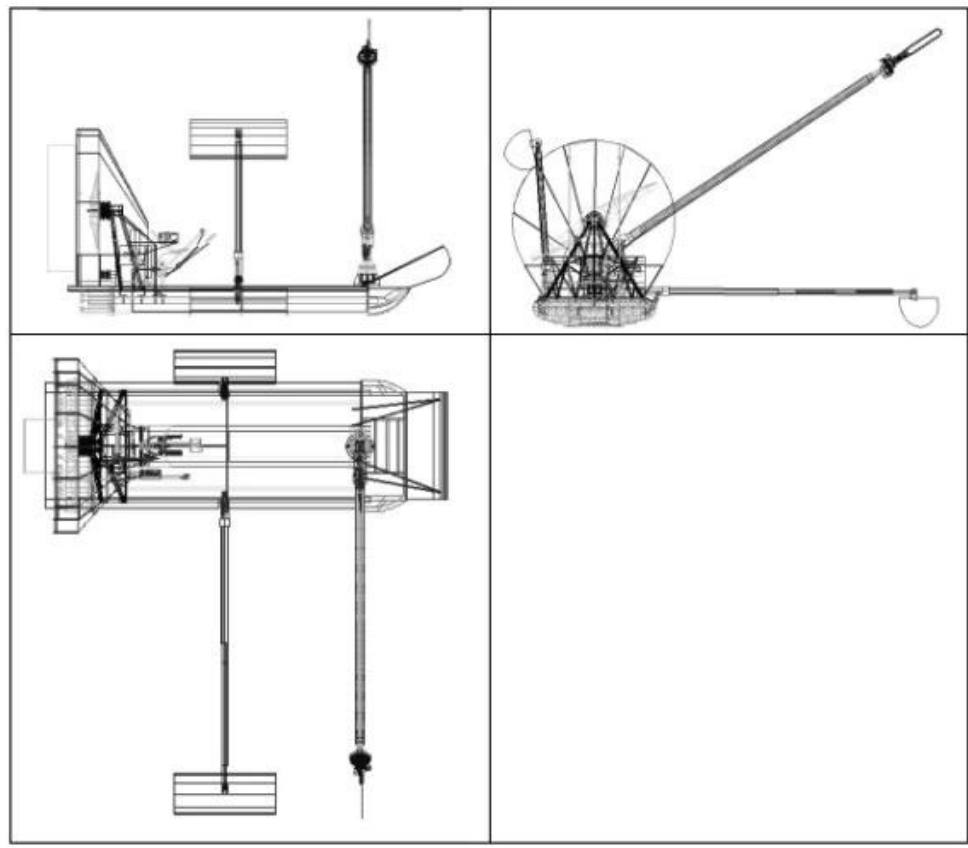

(a)

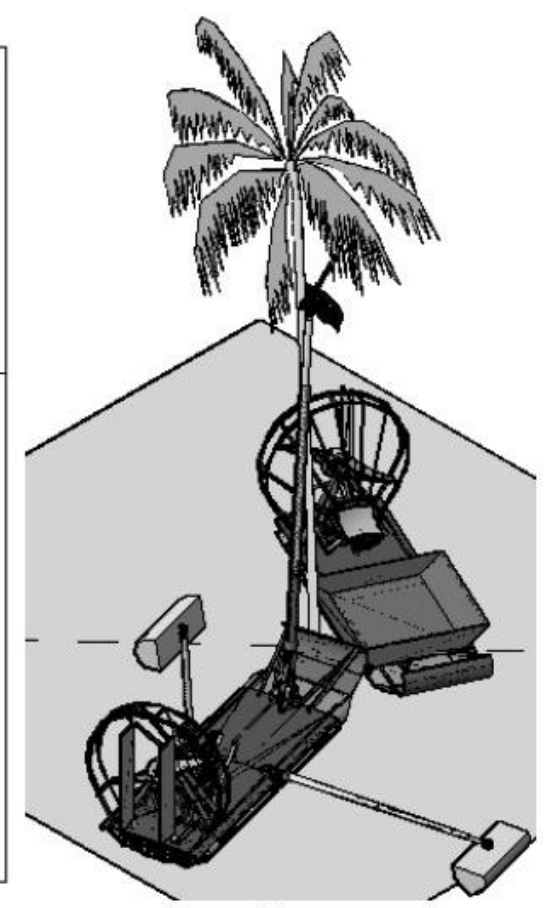

(b) 
Figura 7 - (a) Projeções ortogonais da colhedora de açaí para ambientes de cultivo comercial, (b) Simulação da colhedora de açaí para cultivos comerciais em ação

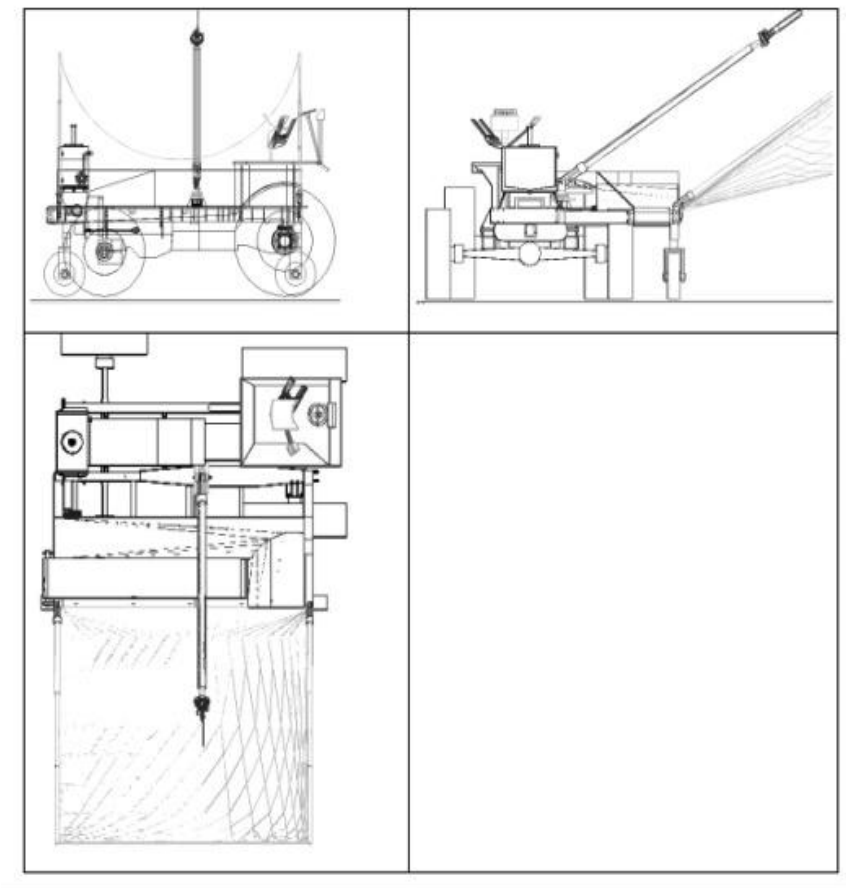

(a)

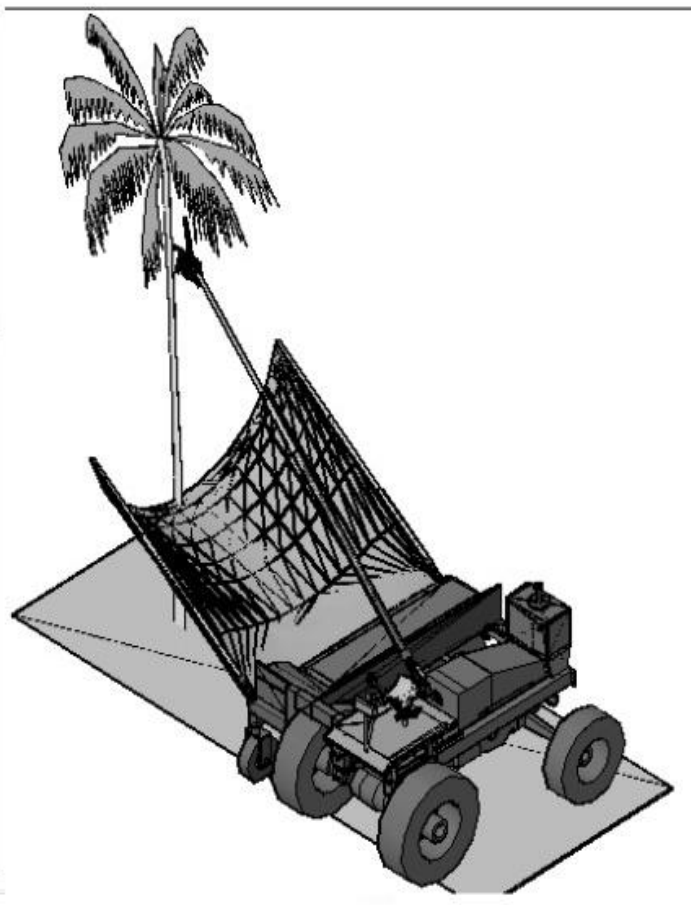

(b)
As escolhas e considerações técnicas seguiram recomendações de Albiero et al. (2007) que prescrevem colhedoras de fácil operação, manutenção, pouco custo de investimento e operação, além de mínimo impacto nos ambientes naturais o que faculta elevar esta atividade do nível primário-extrativista (YUYAMA et al., 2002) para um sistema mecanizado, o que melhorará o poder aquisitivo dos agricultores familiares (WILLERDING; OLIVEIRA, 2005).

O conceito das colhedoras automotrizes de açaí para matas de terra firme e matas de várzea em estação seca pode vir a possibilitar que agricultores familiares obtenham bons resultados com fins comerciais em diversos ambientes, colhendo os frutos com a eficiência sugerida por Vieira et al. (2007).

Pelo projeto conceitual da colhedora para matas alagadas estima-se que o aerobarco pode vir a atender as necessidades de colheita, pois suas dimensões são compatíveis com a navegação por entre matas inundadas como as descritas por Ayres (2006), a capacidade de navegar em chavascais e águas com obstáculos também pôde ser atingida devido ao pequeno calado da embarcação, além de ter maior segurança em regiões com tocos submersos.

Para cultivos comerciais Muller (2009) determina que o espaçamento entre os açaís seja em forma de grade de 5 metros de distância entre palmeiras e 5 metros de espaçamento entre linhas. Portanto, neste tipo de manejo a colhedora de açaís para cultivos comerciais pode vir a ter dimensões compatíveis (Trator de $75 \mathrm{cv}$ com bitola de $1,1 \mathrm{~m}$ ), possibilitando a manutenção do valor nutricional do açaí segundo Menezes et al. (2008).

Outro ponto importante que as novas máquinas podem contribuir é a possibilidade de adoção de sistemas de uso da terra como os agro-ecossistemas ou agroflorestais que podem estocar carbono (SANTOS et al., 2004), o que diminuiria o aquecimento global (SOUZA et al., 2006).

\section{Conclusões}

1. A metodologia de matriz morfológica se mostrou adequada para propor os conceitos de colhedoras de açaí;

2. As novas máquinas propostas podem a vir ter suas estruturas e mecanismos modificados, de acordo com uma avaliação de viabilidade econômica futura;

3. Vislumbra-se pelos conceitos apresentados que as novas colhedoras de açaí poderão operar em ambientes florestais naturais e artificiais, visto suas dimensões 
serem adequadas em relação aos ambientes à que se propõe colher os frutos do açaí.

\section{Agradecimentos} doutorado.

$\mathrm{O}$ primeiro autor agradece ao $\mathrm{CNPq}$ pela bolsa de

\section{Referências}

ALBIERO, D. et al. Proposta de uma máquina para colheita mecanizada de babaçu (Orbignya phalerata Mart.) para a agricultura familiar. Acta Amazônica, v. 37, n. 03, p. 337346, 2007.

ALBIERO, D.; MACIEL, A. J. S; GAMERO, C. A. Desenvolvimento e projeto de colhedora babaçu (Orbignya phalerata Mart.) para a agricultura familiar nas regiões de matas de transição da Amazônia. Acta Amazônica, v. 41, n. 01, p. 57-68, 2011.

AYRES, J. M. As matas de várzea do Mamirauá. Belém: Sociedade Civil Mamirauá, 2006. 123 p.

BACK, N. Metodologia de projeto de produtos industriais. Rio de Janeiro: Guanabara Dois, 1983. 180 p.

CASTRO, A. A floresta em jogo - o extrativismo na Amazônia Central. São Paulo: Editora UNESP, 2000. 250 p.

MENEZES, E. M. S.; TORRES, A. T.; SRUR, A. U. S. Valor nutricional da polpa de açaí (Euterpe oleracea Mart) liofilizada. Acta Amazonica, v. 38, n. 02, p. 355-365, 2008.

MIRANDA, I. P. A.; RABELO, A. Guia de identificação das palmeiras de porto trombetas. Manaus: INPA, 2008. 365 p.

MULLER, A. A. Ambiente Edafo-climático do açaí. Disponível em: <http://sistemasdeproducao.cnptia.embrapa.br/ FontesHTML/Acai/SistemaProducaoAcai_2ed/paginas/edafo. htm>. Acesso em: 20 set. 2009.

NEVES, J. L. M.; MAGAlHÃES, P. S. G.; OTA, W. M. Sistema de monitoramento de perdas visíveis de cana-deaçúcar em colhedora de cana picada. Engenharia Agrícola, v. 24, n. 03, p. 764-770, 2004.

NOGUEIRA, O. L. Introdução e importância econômica. Disponível em: <http://sistemasdeproducao.cnptia.embrapa. br/FontesHTML/Acai/SistemaProducaoAcai_2ed/paginas/intro. htm>. Acesso em: 20 set. 2009.

PAHL, G.; BEITZ, W.; FELDHUSEN, J.; GROTE, K. H. Projeto na engenharia. São Paulo: Edgar Blucher, 2005. 411 p.
PELOIA, P. R.; MILAN, M.; ROMANELLI, T. L. Capacity of the mechanical harversting process of sugar cane billets. Scientia Agricola, v. 67, n. 06, p. 1230-1240, 2010.

QUEIROZ, J. A. L.; MELÉM JUNIOR., N. J. Efeito do tamanho do recipiente sobre o desenvolvimento de mudas de açaí (Euterpe oleracea Mart.). Revista Brasileira de Fruticultura, v. 23, n. 02, p. 460-462, 2001.

RIBEIRO, A. S. S. et al. Utilização dos recursos naturais por comunidades humanas do Parque Ecoturístico do Guamá, Belém, Pará. Acta Amazônica, v. 37 n. 02, p. 123-133, 2007.

ROCHA, E. Potencial ecológico para o manejo de frutos de açaizeiro (Euterpe precatoria Mart.) em áreas extrativistas no Acre, Brasil. Acta Amazônica, v. 34, n. 02, p. 234-244, 2004.

SANTOS, S. R. M.; MIRANDA, I. S.; TOURINHO, M. M. Estimativa de biomassa de sistemas agroflorestais das várzeas do rio Juba, Cametá, Pará. Acta Amazonica, v. 34, n. 01, p. 44-54, 2004

SILVA, B. M. S. et al. Influência da posição e da profundidade de semeadura na emergência de plântulas de açaí (Euterpe oleracea Mart.). Revista Brasileira de Fruticultura, v. 29, n. 01, p. 187-190, 2007

SOUZA, M. A. C. et al. Suco de açaí (Euterpe oleracea Mart.): avaliação microbiológica, tratamento térmico e vida de prateleira. Acta Amazonica, v. 36, n. 04, p. 450-460, 2006.

SRIVASTAVA, A. K. et al. Engineering principles of agricultural machines. St. Joseph: ASABE, 2006. 588 p.

VASCONCELOS, M. A. M.; ALVES, S. M. Colheita e póscolheita de açaí. Disponível em: <http://sistemasdeproducao. cnptia.embrapa.br/FontesHTML/Acai/SistemaProducaoAcai_ 2ed/paginas/colheita.htm>. Acesso em: 10 set. 2009.

VIEIRA, T. A. et al. Sistemas agroflorestais em áreas de agricultores familiares em Igarapé=Açu, Pará: caracterização florística, implantação e manejo. Acta Amazonica, v. 37, n. 04, p. 491-501, 2007.

VIEGAS, I. J. M. et al. Limitações nutricionais para o cultivo de açaizeiro em latossolo amarelo textura média, Estado do Pará. Revista Brasileira de Fruticultura, v. 26, n. 02, p. 382-384, 2004.

VOLPATO, C. E. S.; BRAUNBECK, A. O.; OLIVEIRA, C. A. A. Modelo dinâmico de simulação e otimização da força normal de reação do solo para um mecanismo de corte basal. Engenharia Agrícola, v. 25, n. 02, p. 378-388, 2005.

YUYAMA, L. K. O. et al. Açaí como fonte de ferro: mito ou realidade? Acta Amazonica, v. 32, n. 03, p. 521-525, 2002.

WILLERDING, A. L.; OLIVEIRA, L. A. Diagnóstico de um projeto de enriquecimento florestal na Comunidade do Brasileirinho, Manaus, Amazonas. Acta Amazonica, v. 35, n. 04, p. 521-531, 2005. 